\title{
NOVO REGIME FISCAL: UMA ANÁLISE SOBRE O IMPACTO NOS GASTOS SOCIAIS.
}

\author{
NEW BRAZILIAN FISCAL REGIME: AN ANALYSIS OF THE IMPACT ON SOCIAL \\ SPENDING.
}

Janilson Antonio da Silva Suzart ${ }^{1}$

Ministério da Transparência e Controladoria-Geral da União

suzart@suzart.cnt.br

\begin{abstract}
Resumo
O rebaixamento da nota do Brasil pelas principais agências de classificação de risco de crédito, em 2016, ilustra bem a pioria das finanças públicas do governo federal brasileiro. Com objetivo de alterar esse quadro, foi aprovada o Novo Regime Fiscal (NRF). Diante deste cenário, a presente pesquisa tem como objetivo identificar quais os principais impactos de um limite nos moldes do NRF na execução orçamentária do governo federal brasileiro. Para alcançar este objetivo, foi realizada uma simulação, utilizando os dados dos exercícios de 2008 a 2016. Foram realizadas análises gráficas e testes de comparação entre médias dos valores executados e dos limites simulados. De acordo com os resultados, a aplicação do NRF causaria impacto nas despesas obrigatórias a partir do segundo ano de vigência. Também ficou evidente que a redução das despesas obrigatórias afetará gastos em áreas sociais.
\end{abstract}

Palavras-chave: Novo regime fiscal. Teto de gastos. Orçamento. Áreas sociais. União.

\begin{abstract}
The Brazil's rating downgrading by the main credit rating agencies in 2016 illustrates the worsening of the Brazilian federal government finance. In order to change this framework, the New Fiscal Regime (NRF) was established. Achieving this objective, a simulation was performed using the data from the years 2008 to 2016. Graphical analyzes and comparison tests were performed between averages of the executed values and the simulated limits. According to the results, the application of the NRF would have an impact on the compulsory expenses from the second year of validity. It was also evident that the reduction of compulsory expenditure will affect expenditures in social areas.
\end{abstract}

Keywords: Brazilian new fiscal regime. Spending ceiling. Budget. Social areas. Brazilian federal government.

\section{Introdução}

A Lei Complementar $\mathrm{n}^{\mathrm{o}} 101$ (BRASIL, 2000), mais conhecida como Lei de Responsabilidade Fiscal (LRF) foi um importante marco no controle das finanças dos entes

${ }^{1}$ QMSW 5, LT 7, BL C - Sudoeste - Brasília/DF - CEP 70680-500 
públicos brasileiros. O referido normativo estabeleceu um conjunto de regras que visa uma gestão fiscal responsável, ou seja, em tese, prevenindo os riscos e corrigindo os desvios que pudessem desequilibrar as finanças públicas.

Antes da edição da LRF, os entes públicos brasileiros apresentavam elevado nível de endividamento (SUZART, 2012). Desde a década de 1960 até a década de 1990, o nível de endividamento de tais entes apresentou uma forte tendência de crescimento.

Após a vigência da LRF, os entes públicos brasileiros vinham reduzindo seus níveis de endividamento. De acordo com Suzart (2012), os governos estaduais brasileiros, por exemplo, reduziram os níveis de endividamento durante a década de 2000.

$\mathrm{Na}$ década iniciada em 2010, a situação das finanças dos entes brasileiros voltou a novamente despertar o interesse dos estudiosos do tema e da sociedade, em geral. A crise econômica internacional, oriunda do mercado norte-americano em 2008, afetou o produto interno dos países, os mercados de capitais, as classificações de risco de crédito dos países (riscos soberanos) e as taxas de câmbio (ROSE; SPIEGEL, 2010).

No Brasil, o efeito da crise de 2008 foi sentido um pouco mais tarde. Até o ano de 2012, as commodities no mercado internacional estavam com preços elevados, o que estimulava a economia nacional, "historicamente dependente da exportação de matérias-primas e produtos agrícola" (GARCIA, 2016). Diante do bom desempenho econômico, os entes públicos brasileiros viram suas receitas, em especial as de natureza tributária, crescerem, o que permitiu o aumento dos gastos públicos.

Em 24 de fevereiro de 2016, a Moody's foi a última das grandes agências de classificação de risco de crédito a rebaixar a nota do Brasil (FOLHA DE SÃO PAULO, 2016). Antes, a Fitch e a Standard e Poor's já tinham feito o mesmo. Na prática, o rebaixamento da nota do país representou a visão de que o mercado internacional identificou que a deterioração das finanças públicas brasileiras havia se agravado e que, dada a situação econômica e a instabilidade política vivida pelo país, não haveria uma sinalização no curto prazo de que medidas efetivas seriam tomadas para ajudar na melhoria das condições econômicas brasileiras.

Diante do cenário anteriormente apresentado, emergiu no governo federal brasileiro a proposta de instituir o Novo Regime Fiscal (NRF). Por meio de proposta de emenda à constituição (PEC n 241/2016, na Câmara dos Deputados, convertida na PEC nº 55/2016, no Senado Federal), mais conhecida como a PEC do teto de gastos públicos, buscou-se instituir um novo modelo fiscal para os Orçamentos Fiscal e da Seguridade Social (OFSS) da União, que tem vigência de 20 exercícios financeiros e limitará a despesa primária, que passará a ser 
corrigida pela variação do Índice Nacional de Preços ao Consumidor Amplo (IPCA). A PEC do teto de gastos foi aprovada em dezembro de 2016, convertendo-se na Emenda Constitucional n 95 (BRASIL, 2016).

De acordo com o governo federal brasileiro (CÂMARA DOS DEPUTADOS, 2016a), o $\mathrm{NRF}$ "visa reverter, no horizonte de médio e longo prazo o quadro de agudo desequilíbrio fiscal", por meio da desaceleração do crescimento da despesa pública primária. Alega-se que no período entre 2008 e 2015 a "despesa cresceu 51\% acima da inflação, enquanto a receita evoluiu apenas 14,5\%" (CÂMARA DOS DEPUTADOS, 2016a).

Apesar do difícil cenário das finanças públicas brasileiras, a tramitação da PEC do teto de gastos públicos enfrentou resistência de uma parcela da sociedade. Entre diversos argumentos apresentados, destaca-se que haverá um congelamento dos gastos públicos em áreas sociais sensíveis, tais como, educação e saúde.

O NRF surge como uma tentativa para resgatar o equilíbrio das contas públicas do governo federal brasileiro, de modo similar à edição da LRF. Contudo, a tarefa de reequilibrar as finanças públicas não é tão simples, pois a limitação do crescimento dos gastos públicos tem o potencial de afetar setores sociais sensíveis. Mas, efetivamente quais seriam os principais impactos na execução orçamentária do governo federal ao se estabelecer um teto de gastos públicos?

Percebe-se que a questão anteriormente apresentada não será respondida adequadamente se forem considerados apenas aspectos financeiros ou apenas aspectos sociais. Uma melhor compreensão da execução orçamentária do governo, pode auxiliar no debate sobre os possíveis impactos da proposta de um teto para os gastos.

Diante do que foi até então exposto, a presente pesquisa possui como objetivo principal o seguinte: identificar quais os principais impactos de um limite para o crescimento da despesa orçamentária, nos moldes do NRF, na execução orçamentária do governo federal brasileiro, se a medida tivesse sido implementada entre os anos de 2008 a 2016.

\section{Plataforma teórica}

$2.1 \mathrm{O}$ endividamento estatal

$\mathrm{Na}$ visão econômica clássica, o Estado deve atuar apenas para fomentar a livre concorrência e como fornecedor de bens públicos. A livre concorrência conduziria o mercado ao equilíbrio e à maximização das utilidades (WALRAS, 1983). Todavia, como a livre 
concorrência não ocorre espontânea e automaticamente, cabendo assim ao Estado o papel de promovê-la.

De acordo com a visão econômica clássica, o papel do Estado seria secundário, visto que na presença da livre concorrência, haveria um autorregulação do mercado, de acordo com a oferta e a demanda de bens. Até os gastos estatais seriam dependentes do desenvolvimento econômico, ou seja, quando houvesse crescimento econômico haveria aumento nos gastos públicos (WAGNER apud BAĞDIGEN; ÇETINTAŞ, 2004).

No papel de fornecedor de bens públicos, o Estado se limitaria ao fornecimento daqueles que não fossem ofertados pelo setor privado. Teoricamente, um bem público é aquele cujo consumo por um indivíduo não leva à subtração do consumo daquele bem por qualquer outro indivíduo (SAMUELSON, 1954).

Em razão da dificuldade de evitar o uso de um bem público, dificilmente o setor privado teria o interesse de ofertá-lo, pois não teria como se financiar. Tal fato faria com que o fornecimento de bens públicos ficasse, quase que exclusivamente, por conta do Estado. Desse modo, uma parcela significativa dos gastos públicos seria destinada à oferta de tais bens.

Em sentido oposto à visão clássica, Keynes (1936) descreve que o papel do Estado deve ser de intervenção direta no ambiente econômico e não apenas de fomento à livre concorrência. O setor privado seria incapaz de maximizar a utilidade de todos os agentes econômicos e somente a atuação estatal poderia conduzir ao pleno emprego.

De acordo com Keynes (1936), nos momentos de recessão do ciclo econômico caberia ao Estado o papel de estimular a demanda efetiva, mesmo que para isto tivesse que provocar déficits no orçamento estatal.

$\mathrm{Na}$ visão keynesiana, os gastos estatais seriam capazes de estimular o crescimento econômico. Tal impacto seria mais facilmente notado nos períodos de recessão econômica. Naturalmente, nestes períodos, o setor privado tenderia a reduzir o nível de investimentos, afetando a produção e a renda e, consequentemente, afetando o desenvolvimento econômico.

Conforme foi descrito anteriormente, Keynes (1936) defendeu a ideia de que nos períodos recessivos, o Estado deveria intervir na economia, mesmo que tivesse que incorrer em déficits. Todavia, essa assertiva não deve ser entendida como uma permissão para déficits sucessivos. De acordo com Bresser-Pereira (2006), Keynes não defendeu déficits públicos crônicos, ou seja, o Estado deveria buscar sempre o equilíbrio fiscal, somente recorrendo aos déficits por um período breve até que o nível de emprego fosse reestabelecido. 
O modelo governamental brasileiro é mais próximo da visão keynesiana do que da visão clássica. A Constituição Federal de 1988 consagrou como direitos sociais: (a) educação; (b) saúde; (c) alimentação; (d) trabalho; (e) moradia; (f) lazer; (g) segurança; (h) previdência social; (i) proteção à maturidade e à infância; e (j) assistência aos desamparados (BRASIL, 1988). Desse modo, cabe ao Estado brasileiro a oferta de bens e serviços que proporcionem meios de acesso a tais direitos.

Para financiar os gastos públicos, visando o atendimento das despesas com direitos sociais e com as demais áreas, o Estado brasileiro possui, basicamente, quatro fontes de recursos: (a) a prestação direta de serviços ou da venda/exploração de bens; (b) a tributação; (c) a emissão de moeda; e (d) a obtenção de empréstimos (SUZART, 2012).

As três primeiras fontes podem não ser adequadas nos momentos de recessão econômica. A sua vez, o endividamento permite, no primeiro momento, o aumento dos gastos estatais sem afetar diretamente a renda disponível para o consumo, estimulando o crescimento econômico. Em momentos recessivos, o aumento da receita (tributária e não tributária) não é, muitas vezes, possível, bem como, a emissão de moeda é capaz de alimentar processos inflacionários. Desse modo, o endividamento é uma fonte que permite a rápida expansão dos gastos públicos.

Todavia, apesar de ser uma fonte adequada nos momentos de recessão econômica, o uso do endividamento possui uma desvantagem. Contrair dívidas implica em comprometer receitas futuras com o pagamento de juros e encargos e a devolução do principal. Ademais, não é possível contrair dívidas indefinidamente.

Além de comprometer a capacidade de realização de gastos no futuro, o Estado precisará comprovar que reúne condições para arcar com os empréstimos. Quanto melhor forem as condições estatais, em especial a situação econômico-financeira, menores tendem a ser os custos dos empréstimos contraídos ou da emissão de títulos e vice-versa. As agências de classificação de risco de crédito buscam sintetizar as condições estatais por meio de classificações que demonstram, em tese, o risco de inadimplência de tais entes.

Segundo Alesina e Perotti (1999), nas décadas de 1970 a 1990, muitos países-membro da Organização para a Cooperação e Desenvolvimento Econômico (OCDE) possuíam elevados déficits públicos, por fazerem uso intensivo do endividamento para custear os gastos públicos. Essa situação exigiu que tais países reorganizassem suas finanças para melhorar seus desempenhos financeiros e garantir estabilidade econômica.

Um exemplo de um país que não fez os ajustes necessários foi a Grécia. Em outubro de 2009, o país anunciou que havia subavaliado seus déficits ao longo de vários anos e que, 
portanto, apresentava uma situação financeira bastante grave. No ano seguinte, o mercado se recusou a fornecer novos empréstimos para a Grécia e a falência do estado grego não ocorreu porque o Fundo Monetário Internacional, o Banco Central Europeu e a Comissão Europeia ajudaram o país com cerca de 240 bilhões de euro (NEW YORK TIMES, 2016).

Reinhart e Rogoff (2010) destacam que em economias emergentes, elevados níveis de endividamento estão associados ao crescimento econômico, mas também, a elevados níveis de inflação. Segundo os autores, para os países desenvolvidos, o endividamento elevado não demonstrou uma forte associação com o crescimento econômico.

Na continuação, passa-se à análise sobre o Novo Regime Fiscal, considerando, em especial, o contexto da gestão fiscal dos entes públicos brasileiros, nas últimas décadas.

\subsection{O Novo Regime Fiscal}

O Novo Regime Fiscal (NRF) foi criado pela Emenda Constitucional n ${ }^{\circ} 95$ (BRASIL, 2016), é aplicável às entidades da União que integram os Orçamentos Fiscal e da Seguridade Social (OFSS) e vigorará por vinte exercícios financeiros, a partir de 2017.

O NRF estabelece limites individualizados (teto de gastos) para os Poderes da União (Executivo, Legislativo e Judiciário), Ministério Público da União, Conselho Nacional do Ministério Público e Defensoria Pública da União da seguinte forma (BRASIL, 2016):

- Para o exercício de 2017, o limite será igual à despesa primária paga no exercício de 2016, corrigida em 7,2\%; e

- Para os exercícios seguintes, o limite será igual ao limite do exercício anterior, corrigido pelo Índice Nacional de Preço ao Consumidor Amplo (IPCA) (ou outro índice que o substituir), para o período de doze meses encerrado em junho do exercício anterior.

Na prática, o NRF estabeleceu um limite para o crescimento das despesas primárias do governo federal. Tal limite foi individualizado para garantir uma harmonia e respeitar a independência entre os Poderes e entidades constitucionais, de modo parecido aos limites estabelecidos pela LRF.

As despesas primárias compreendem aquelas que afetam o resultado primário, ou seja, de modo geral, compreendem o total das despesas dos OFSS, deduzido das despesas financeiras (amortização de dívidas, concessão de empréstimos e juros passivos) (SECRETARIA DO TESOURO NACIONAL, 2012). A Emenda Constitucional $n^{\circ} 95$ excluiu algumas despesas primárias, que deixaram de compor a base de cálculo dos limites anteriormente citados. 
De acordo com o NRF, nos três primeiros exercícios financeiros, o Poder Executivo poderá reduzir o seu limite, em até $0,25 \%$, para aumentar o limite dos demais Poderes e entidades constitucionais (BRASIL, 2016). Nota-se que esta regra de transição pode auxiliar os demais Poderes e entidades a adequarem seus gastos aos seus futuros limites. Sendo o Poder Executivo aquele com a maior fatia dos OFSS, caberá a ele oferecer uma pequena parte de seu limite para auxiliar os demais.

Outra condição estabelecida pelo NRF (BRASIL, 2016) é que, respeitado os limites estabelecidos para os Poderes e entidades constitucionais, a Lei de Diretrizes Orçamentárias (LDO) poderá dispor sobre a compensação entre os limites dos órgãos citados na Emenda Constitucional $n^{\circ} 95$.

A partir do décimo ano de vigência do NRF (ou seja, a partir de 2027), o método de correção dos limites individualizados poderá ser revisto por iniciativa do Presidente de República, por intermédio de lei complementar e apenas uma vez por mandato (BRASIL, 2016).

Na verificação do teto de gastos, as despesas primárias incluirão os restos a pagar pagos e as demais operações que afetarem o resultado primário no respectivo exercício (BRASIL, 2016). Ainda em relação ao limite, pode-se excluir o pagamento de restos a pagar inscritos até 2015, no montante até o excesso de resultado primário dos OFSS em relação à meta fixada na LDO.

A Emenda Constitucional $n^{\circ} 95$ descreve que, quando ocorrer o descumprimento de limite individualizado, o Poder ou entidade constitucional sofrerá vedações que vigorarão até o final do exercício de retorno das despesas ao respectivo limite, sem prejuízo a outras medidas (BRASIL, 2016).

Em especial para o Poder Executivo, além das vedações acima citadas, quando houver o descumprimento do limite individualizado, existirá mais duas vedações, de acordo com o NRF (BRASIL, 2016): (a) criação ou expansão de programas e linhas de financiamento, bem como a remissão, renegociação ou refinanciamento de dívidas que impliquem ampliação das despesas com subsídios e subvenções; e (b) concessão ou a ampliação de incentivo ou benefício de natureza tributária. Para todos os Poderes e entidades constitucionais ainda existe a vedação de realização da revisão geral anual de remuneração dos agentes públicos, ou seja, não é possível alterar a remuneração (conceder reajustes ou aumentos) na remuneração paga aos agentes públicos (servidores, empregados, membros dos poderes etc.). 
O NRF também alterou os valores para aplicações mínimas em ações e serviços públicos de saúde e de manutenção e desenvolvimento do ensino. De acordo com o NRF (BRASIL, 2016), para o exercício de 2017, os valores para as aplicações mínimas serão aqueles definidos na Constituição Federal (BRASIL, 1988): (a) 15\% da receita corrente líquida, para as ações e serviços públicos de saúde; e (b) 18\% da receita resultante de impostos, para a manutenção e desenvolvimento do ensino. Para os exercícios seguintes, os valores para as aplicações mínimas serão aqueles do exercício anterior, corrigidos pelo IPCA.

Também houve alteração no caso da obrigatoriedade de execução das emendas parlamentares individuais. Segundo o NRF (BRASIL, 2016), para o exercício de 2017 continua valendo o dispositivo constitucional, ou seja, o limite de $1,2 \%$ da receita corrente líquida (BRASIL, 1988). Para os exercícios seguintes, o novo limite será igual ao limite do exercício anterior, corrigido pelo IPCA.

Quando o Poder Executivo encaminhar o Projeto de Lei Orçamentária Anual (PLOA), deve demonstrar os valores máximos de gastos, de acordo com o limite individualizado, segundo o NRF (BRASIL, 2016). Por esse motivo, a correção a partir do exercício de 2017, levará em consideração o IPCA acumulado em doze meses encerrado em junho, pois o prazo para o envio do PLOA é 31 de agosto.

As despesas primárias autorizadas na Lei Orçamentária Anual não podem exceder os limites individualizados do NRF (BRASIL, 2016). Além disso, não é possível a abertura de crédito suplementar ou especial que amplie o total das despesas primárias, além dos limites individualizados do NRF (BRASIL, 2016).

Além de exigir que o PLOA respeite os limites individualizados, o NRF (BRASIL, 2016) estabelece que a proposição legislativa, que crie ou altere despesa obrigatória ou renúncia de receita, contenha a estimativa de seu impacto orçamentário e financeiro.

Diante das características do NRF, pode-se concluir que ele estabelece regras que facilitarão o alcance da meta de resultado primário por parte do governo federal. Havendo respeito aos limites estabelecidos, o crescimento da despesa primária estará sujeito ao teto de gastos. Todavia, o NRF somente conseguirá atingir seus objetivos, se as demais limitações legais forem igualmente respeitadas.

O NRF, em tese, permitirá uma melhor gestão do endividamento público. Havendo crescimento das receitas primárias, haverá crescimento do resultado primário e, consequentemente, mais recursos disponíveis para propiciar a redução do endividamento ou melhores condições (redução da taxa de juros, por exemplo) para a gestão da dívida pública. 
Entretanto, o NRF alterou os valores de aplicações mínimas nas áreas da educação e da saúde. As alterações de tais valores significam que o governo federal, a partir de 2018, possuirá um valor menor como limite mínimo de gastos com educação e saúde. Todavia, o montante a ser gasto poder ser superior ao limite mínimo, sendo essa uma escolha dos gestores federais.

Em sentido prático, a redução ou não de gastos nas áreas sociais será decorrente das escolhas dos gestores e da limitação de recursos. Se a escolha for pela manutenção ou crescimento dos gastos sociais, haverá menos recursos para as demais despesas primárias, como, por exemplo, a construção ou a recuperação de uma rodovia. Em sentido contrário, outras áreas, que não as sociais, serão atendidas, não sendo, portanto, uma escolha trivial.

No próximo item, é realizada a discussão sobre o risco de inadimplência dos governos nacionais.

\section{$2.3 \mathrm{O}$ risco de inadimplência}

De acordo com Datz (2014), a inadimplência faz parte do dia-a-dia do setor público, desde que os Estados foram formados. A inadimplência (ou moratória) compreende a suspensão do pagamento do principal ou dos juros da dívida. Como exemplo recente, cita-se a Grécia, que em 2015, anunciou que ficaria inadimplente com o Fundo Monetário Internacional em cerca de US\$ 1,7 bilhão (CNN MONEY, 2015).

A decisão de se tornar inadimplente não é sempre embasada em questões técnicas. Reinhart e Rogoff (2009) afirmam que tal decisão resulta de um complexo cálculo de custobenefício que envolve, também, considerações políticas e sociais. Os entes públicos precisam decidir o quanto podem reservar de seus recursos para o pagamento de suas dívidas. Quanto mais recursos para o pagamento das suas dívidas, menos recursos haverá para prestar serviços e oferecer produtos para a sua população e vice-versa.

Em um primeiro momento pode parecer que seria mais fácil para os gestores escolher ofertar produtos e serviços à sua população do que efetuar o pagamento aos credores, em uma situação de escassez de recursos. Porém, existem motivos para que os países honrem seus compromissos. Entre os principais motivos, Rose (2005) destaca que: (a) os ativos dos países inadimplentes em território estrangeiro podem ser apreendidos ou sofrer restrições de uso; (b) os credores podem não fornecer novos empréstimos em momentos futuros; e (c) os países inadimplentes podem sofrer retaliações ou reduções de benefícios no comércio internacional. 
Nota-se que a própria população pode ser fortemente afetada pela decisão de seu respectivo país de se tornar inadimplente. Assim, o benefício inicial de não ter interrupção na oferta de bens e serviços, pode vir acompanhando da incerteza da continuação desta oferta em um momento futuro. Conforme foi visto anteriormente, o endividamento é uma das fontes de financiamento do Estado e a ausência de credores que queiram fornecer ou a pioria das condições para novos empréstimos pode afetar mais ainda a situação financeira do ente público.

Ao contrário do que ocorre com as entidades privadas, não existe uma norma internacional ou um tribunal internacional aceito por todos os países e constituído com o objetivo de analisar os casos de inadimplência dos países. As transações são realizadas a partir da reputação desses países e das expectativas dos credores. Grossman e Huyck (1988) descrevem que uma boa reputação é de grande importância pois fornece um acesso facilitado aos empréstimos.

Grossman e Huyck (1988) complementam que, como nem sempre é possível obrigar os países a realizar o pagamento de suas dívidas, como pode ocorrer com as entidades privadas, a decisão de um país em não postergar o pagamento de suas dívidas dependerá da preocupação desse com a sua reputação para validar a expectativa de seus credores. Uma boa proxy da reputação dos países são as opiniões (notas) das agências de classificação de risco de crédito.

A partir de análises de informações quantitativas e qualitativas sobre o risco de inadimplência dos devedores, as agências de classificação de risco de crédito emitem opiniões sobre tais devedores (BRITO; PIMENTEL, 2012). Em relação aos entes públicos, as agências costumam avaliar a capacidade de um ente público, seja ele nacional ou subnacional, para honrar os pagamentos acordados (SUZART, 2014).

No caso brasileiro, recentemente, observou-se que as principais agências de classificação do risco de crédito (Standard e Poor's, Moody's e Fitch) realizaram rebaixamento da nota do Brasil (FOLHA DE SÃO PAULO, 2016). Estes rebaixamentos indicam que, nas análises realizadas por tais agências, houve evidências de que aumentou o risco de inadimplência do governo federal brasileiro.

Diante da forte contração da economia mundial, efeito da crise no mercado internacional iniciada em 2008, houve forte contração das receitas do governo brasileiro. Isto, aliado à dificuldade de redução dos gastos públicos, levou as finanças públicas do país a vivenciar uma situação de descontrole que foi refletida na opinião das agências.

Nos últimos anos, a relação entre o endividamento do governo federal brasileiro e o produto interno bruto (PIB) foi em média de 60\%, de acordo com o Banco Mundial (WORLD 
BANK, 2016). Em novembro de 2016, a dívida pública, mobiliária e contratual, do governo federal importou em cerca de R\$ 3,1 trilhões (SECRETARIA DO TESOURO NACIONAL, 2016).

O endividamento do governo federal brasileiro é um dos itens relevantes na análise sobre o risco de inadimplência. Hilscher e Nosbusch (2010), em uma análise sobre os fatores que afetam os preços dos títulos de dívida emitidos por 31 países emergentes, de 1994 a 2007, identificaram que, quanto maior for a relação entre a dívida e o PIB, maior a taxa de juros paga pelo país. Complementa-se que maiores taxas de juros são correlacionadas com maior percepção de risco por parte dos credores.

Nesse mesmo sentido de quanto maior a taxa, maior o risco, Hilscher e Nosbusch (2010) identificaram em um modelo logístico que, quanto maior for a relação entre a dívida e o PIB, maior a probabilidade de um país se tornar inadimplente. Observa-se que o controle do endividamento é de fundamental importância para que os entes públicos possam obter acesso a novos empréstimos em melhores condições.

Em relação ao comércio internacional, Rose (2005) destaca que os credores podem desencorajar a inadimplência com punições diretas ou indiretas aos países. Quando possível, os credores podem estabelecer cláusulas ou impor restrições que causem redução direta do montante transacionado entre os países (geralmente, quando o credor é outro país ou uma organização multigovernamental).

A punição na forma indireta decorre, em geral, mais da inadimplência do ente público do que da atuação do credor. Segundo Rose (2005), a inadimplência pode naturalmente gerar uma redução na oferta do crédito comercial de curto prazo, o instrumento mais utilizado para financiar a maior parte do comércio internacional. Tendo as entidades privadas nacionais dificuldades para acessar o crédito comercial de curto prazo, terminariam por não efetuar ou reduzir o volume de suas transações internacionais.

Em ambos os cenários, novamente, a população sofre as consequências da inadimplência do ente estatal, em especial, em países em desenvolvimento. Tais países não conseguem produzir internamente muitos dos gêneros básicos que são consumidos por sua população e necessitam do comércio internacional para suprir essas demandas. Restrições nas transações comerciais internacionais podem aumentar os preços ou causar a escassez de tais produtos no mercado nacional.

Observa-se que a inadimplência tem consequências graves, tanto para as finanças do ente público, quanto para a sua população. Assim, além de buscar se manter adimplente, o ente 
público necessita gerenciar o seu nível de endividamento, para que áreas sociais sensíveis não sofram com reduções evitáveis de gastos e consequente redução na oferta de produtos e serviços à população.

O uso racional do endividamento, como fonte de recursos para o Estado, propicia uma redução do risco de inadimplência, amplia as facilidades para acessar o mercado de crédito e aumenta o controle das finanças públicas.

\section{Procedimentos metodológicos}

O objetivo principal da presente pesquisa é identificar quais os principais impactos que um teto de gastos, nos modelos do NRF, pode causar na execução orçamentária do governo federal brasileiro. Considerando que o NRF passou a vigorar a partir de 2017, optou-se pela simulação dos efeitos do teto de gastos como se a medida tivesse sido implementada entre os anos de 2008 a 2016.

O exercício de 2008 será considerado como o ano-base da simulação. A partir dos dados da execução realizada naquele exercício, será calculado o limite para o exercício de 2009, sendo o valor corrigido pelo IPCA acumulado em doze meses, até junho de 2008. E, repetindo-se essa estratégia, serão calculados os limites dos exercícios posteriores, ou seja, atualizando-se pelo IPCA o limite do exercício anterior.

Para fins de simplificação da análise, não serão computados limites individualizados como explicitado pela NRF. Na simulação será utilizado o limite global da União, sem observação das especificidades de cada Poder ou entidade constitucional. Para o alcance do objetivo da pesquisa, a análise do limite global se demonstra suficiente.

Para o cômputo do limite, será considerada a despesa primária paga acrescida do pagamento de restos a pagar do exercício de 2008. A despesa primária corresponde ao total da despesa orçamentária excluído das despesas com amortização de dívidas, com concessão de empréstimos e com juros e encargos da dívida. Também foram excluídas as operações que não afetaram o resultado primário (transferências constitucionais, aumento de capital das empresas estatais não dependentes etc.).

Os dados sobre a execução orçamentária foram obtidos no sítio do Siga Brasil (https://www12.senado.leg.br/orcamento/sigabrasil). O Siga Brasil é de livre acesso e contém as informações sobre o orçamento federal, extraídos do Sistema Integrado de Administração Financeira do Governo Federal, o SIAFI. Os valores do IPCA foram obtidos no sítio do Instituto 
Brasileiro de Geografia e Estatística (IBGE) (http://www.ibge.gov.br/home/estatistica/indicado res/precos/inpc_ipca/defaultinpc.shtm).

A partir das informações obtidas, foram computadas três séries: (a) gastos totais, compreendendo o total da despesa primária paga conforme critérios do NRF; (b) limites simulados, compreendendo a despesa primária paga de 2008 corrigida pelo IPCA, exercício a exercício; e (c) gastos obrigatórios, compreendendo a parcela da despesa primária paga que possui execução obrigatória.

Os gastos obrigatórios são aqueles nos quais o gestor público não possui discricionariedade quanto à determinação do seu montante e do seu momento de realização (SECRETARIA DE ORÇAMENTO FEDERAL, 2016). Em termos práticos, a despesa primária pode ser dividia em duas parcelas: (a) uma obrigatória; e (b) outra discricionária.

Inicialmente foi considerado o limite total ao qual estaria sujeito à União. Na sequência foram escolhidas seis áreas para análise da evolução dos gastos realizados (totais e obrigatórios) e os limites simulados: (a) segurança pública; (b) assistência social; (c) previdência social; (d) saúde; (e) educação; e (f) transporte. Para a análise das áreas específicas, foi computado um limite para cada área nos mesmos moldes que o limite total.

Destaca-se que os limites para as áreas têm por objetivo servir de parâmetro para comparação entre os valores. O NRF não estabeleceu limites individualizados por área de atuação governamental, mas tão somente por Poderes e entidades constitucionais. Os limites simulados têm apenas caráter didático e permitem uma melhor ilustração dos efeitos que o teto de gastos irá causar no momento de elaboração e execução da proposta orçamentária.

Com o objetivo de comparar os comportamentos dos valores gastos (totais e obrigatórios) e dos limites simulados foi escolhida a técnica de análise gráfica. A ideia é identificar as tendências e as possíveis anormalidades nos comportamentos das séries analisadas.

Complementando a análise gráfica, foram realizados testes de comparação entre as médias dos valores totais gastos e dos limites simulados. $\mathrm{O}$ objetivo foi verificar se as séries possuíam diferenças estatisticamente significativas. Inicialmente foram analisadas as estatísticas descritivas e foi realizado o teste de Shapiro-Wilk. Este último teste serviu para a escolha do teste de comparação entre médias, do seguinte modo: (a) se as séries possuíssem distribuição normal, seria realizado o teste t de Student; e (b) senão, seria utilizado o teste de Mann-Whitney.

Em todos os testes realizados foi considerado o nível de significância de 5\%. 


\section{Análise dos resultados}

Inicialmente é apresentado o gráfico contendo as despesas primárias da União, valores realizados e simulados, entre o exercício de 2008 e o de 2016.

Figura 1 - Gráfico - Despesas primárias da União - 2008 a 2016.

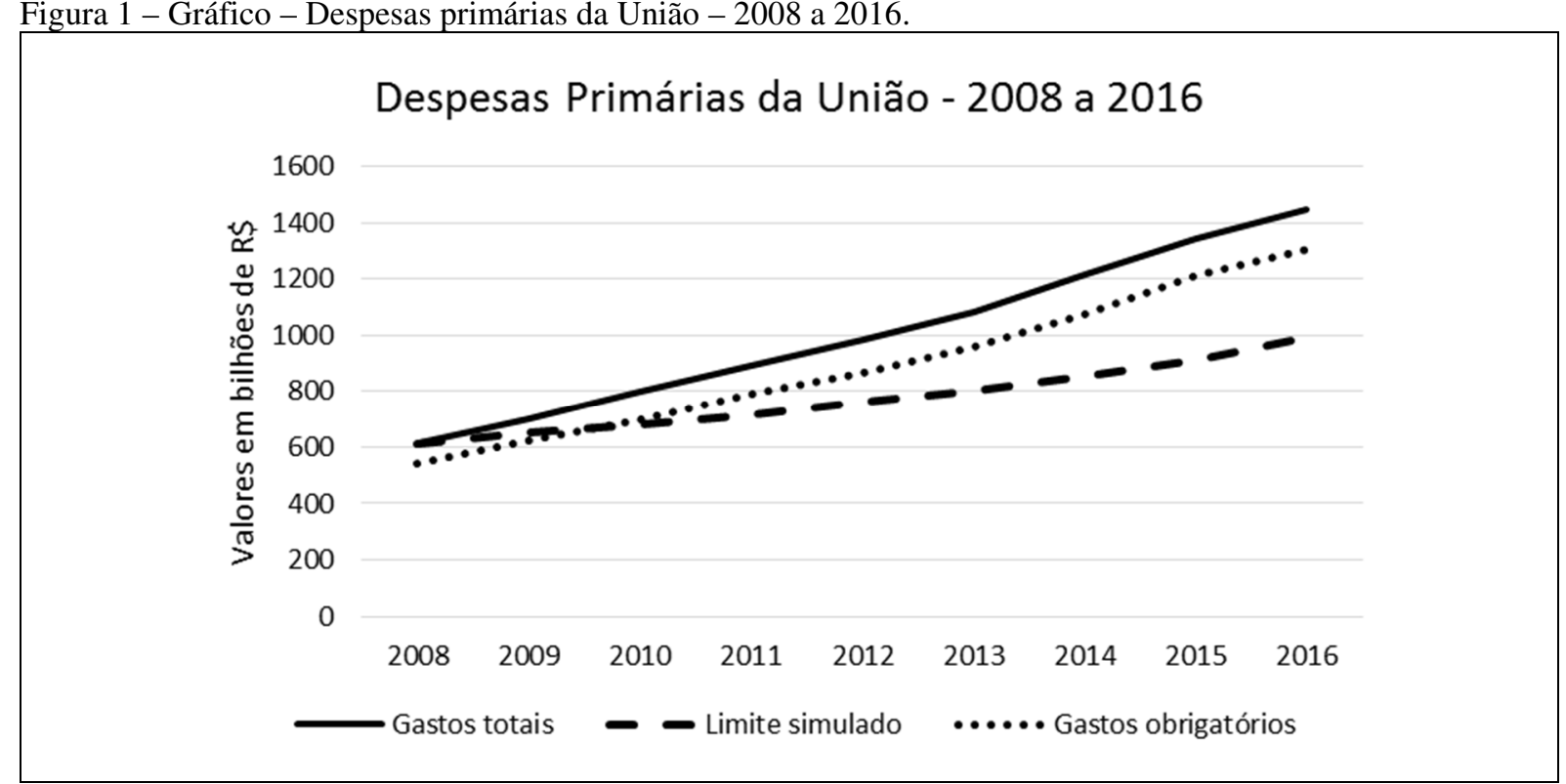

Fonte: Elaboração própria a partir das informações do Senado Federal (2017).

Em relação à comparação entre os gastos totais e os limites simulados, nota-se que, nominalmente os gastos totais foram superiores. Assim sendo, pode-se afirmar que as despesas primárias da União cresceram, nominalmente, em percentual superior ao IPCA acumulado em dozes meses.

Caso o limite já estivesse em vigor desde 2009, por exemplo, no exercício de 2016, o governo federal teria que reduzir a execução das despesas primárias em cerca de $31,6 \%$, ou seja, R\$ 314 bilhões. Todavia, a tarefa não seria tão simples, em função das despesas obrigatórias.

Comparando-se, nominalmente, os gastos obrigatórios com o limite simulado, observase que apenas no ano de 2009, os gastos obrigatórios estavam abaixo do limite simulado. Isto significa que, caso o limite já estivesse vigente, os gestores federais teriam que promover reduções no crescimento dos gastos obrigatórios, a partir de 2010, ou seja, no segundo ano de implementação do limite.

Conforme explicitado anteriormente, as alterações nas despesas obrigatórias são mais complicadas do que as com as despesas discricionárias. Em relação a estas últimas, o próprio gestor pode reduzir seus montantes na proposta orçamentária. As despesas obrigatórias têm seu 
crescimento vinculado a condições estabelecidas em dispositivos legais. A alteração do crescimento das despesas obrigatórias necessita de alteração de tais dispositivos.

No ano de 2009, nas condições simuladas, ainda haveria margem para que o corte ocorresse nos gastos discricionários. Todavia, a partir de 2010, o corte teria que ocorrer nos gastos obrigatórios, o que não dependeria apenas do NRF, mas de outras reformas em diversas áreas.

Na continuação, a simulação volta-se para as áreas específicas escolhidas na presente pesquisa.

Figura 2 - Gráficos - Despesas primárias da União - Por áreas específicas - 2008 a 2016.

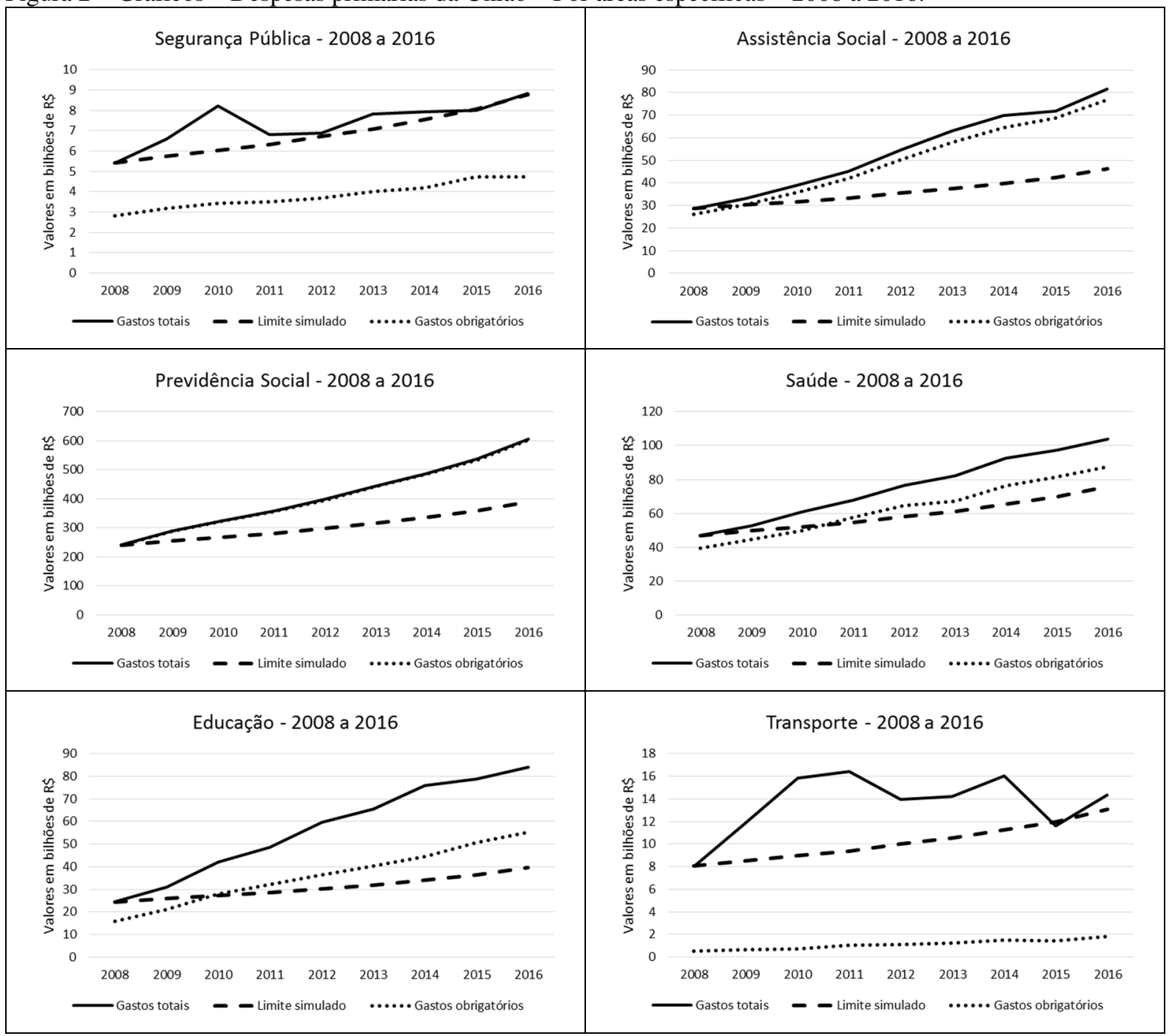

Fonte: Elaboração própria a partir das informações do Senado Federal (2017).

A partir das análises dos gráficos anteriormente apresentados, observa-se três situações distintas, que se repetem em outras áreas de atuação estatal. 
Nas áreas de segurança pública e de transporte, verificou-se que os gastos realizados foram, nominalmente, superiores aos limites calculados, na maioria dos exercícios (a exceção foi o ano de 2015). Nestas áreas, os gastos obrigatórios foram, nominalmente, inferiores aos limites calculados.

Considerando-se que o teto de gastos impactaria até os gastos obrigatórios, de acordo com a simulação realizada, áreas com o mesmo comportamento como o da segurança pública e o de transporte seriam aquelas nas quais os gestores federais conseguiriam uma redução mais rápida por meio de corte nas despesas discricionárias. A área de transporte, por exemplo, em média, apenas $8,2 \%$ do total dos gastos primários é considerado obrigatório.

Nas áreas de saúde e de educação, foi observado que os gastos totais foram sempre superiores aos limites calculados, em termos nominais. Os gastos obrigatórios destas áreas foram, nominalmente, maiores do que os limites calculados, na maior parte do período analisado (a partir de 2011, mais especificamente).

Em áreas semelhantes às da saúde e da educação, novamente os gestores federais encontrariam margens para a redução de gastos por intermédio da redução das despesas discricionárias. No período analisado, as despesas discricionárias médias das áreas da saúde e da educação foram de $16,4 \%$ e $36,4 \%$, respectivamente, do montante total de cada área.

Nas áreas da assistência social e da previdência social, os gastos realizados foram, nominalmente, superiores aos limites calculados em todos os exercícios, desde 2009. Nestas áreas os gastos obrigatórios foram, nominalmente, superiores na maioria dos exercícios analisados.

A principal característica das áreas semelhantes às de assistência social e de previdência social é que os gastos obrigatórios compreendem a maior parcela dos gastos totais. $\mathrm{Na}$ área de previdência social essa relação é 99,6\%, o que pode ser observado na sobreposição das linhas dos gastos totais e dos gastos obrigatórios. Essa relação foi de cerca de $93 \%$ na área de assistência social.

$\mathrm{Na}$ tabela a seguir, são apresentados as estatísticas descritivas e os resultados do teste Shapiro-Wilk. 
Tabela 1 - Estatísticas descritivas e resultados do teste Shapiro-Wilk.

\begin{tabular}{|c|c|c|c|c|c|c|c|c|}
\hline \multicolumn{2}{|c|}{ Despesas primárias } & Mínimo & Máximo & Média & $\begin{array}{l}\text { Desvio- } \\
\text { Padrão }\end{array}$ & Assimetria & Curtose & $\begin{array}{c}\text { Shapiro- } \\
\text { Wilk }\end{array}$ \\
\hline \multirow{2}{*}{ União } & Total & 612,465 & $1.446,291$ & $1.007,543$ & 287,674 & 0,166 & 1,788 & 0,967 \\
\hline & Limite & 612,465 & 991,606 & 775,173 & 126,168 & 0,382 & 2,006 & 0,966 \\
\hline \multirow{2}{*}{$\begin{array}{l}\text { Segurança } \\
\text { Pública }\end{array}$} & Total & 5,415 & 8,826 & 7,386 & 1,045 & $-0,521$ & 2,447 & 0,944 \\
\hline & Limite & 5,415 & 8,767 & 6,853 & 1,115 & 0,382 & 2,006 & 0,966 \\
\hline \multirow{2}{*}{$\begin{array}{l}\text { Assistência } \\
\text { Social }\end{array}$} & Total & 28,585 & 81,401 & 54,061 & 18,646 & 0,019 & 1,623 & 0,951 \\
\hline & Limite & 28,585 & 46,280 & 36,179 & 5,889 & 0,382 & 2,006 & 0,966 \\
\hline \multirow{2}{*}{$\begin{array}{l}\text { Previdência } \\
\text { Social }\end{array}$} & Total & 240,683 & 605,351 & 409,337 & 119,583 & 0,218 & 1,960 & 0,981 \\
\hline & Limite & 240,683 & 389,676 & 304,623 & 49,581 & 0,382 & 2,006 & 0,966 \\
\hline \multirow{2}{*}{ Saúde } & Total & 46,888 & 103,931 & 75,634 & 20,101 & $-0,027$ & 1,685 & 0,960 \\
\hline & Limite & 46,888 & 75,914 & 59,345 & 9,659 & 0,382 & 2,006 & 0,966 \\
\hline \multirow{2}{*}{ Educação } & Total & 24,387 & 84,088 & 56,619 & 21,428 & $-0,198$ & 1,676 & 0,945 \\
\hline & Limite & 24,387 & 39,483 & 30,866 & 5,024 & 0,382 & 2,006 & 0,966 \\
\hline \multirow{2}{*}{ Transporte } & Total & 8,065 & 16,403 & 13,582 & 2,679 & $-0,910$ & 2,936 & 0,895 \\
\hline & Limite & 8,065 & 13,058 & 10,208 & 1,661 & 0,382 & 2,006 & 0,966 \\
\hline
\end{tabular}

Fonte: Elaboração própria a partir das informações do Senado Federal (2017).

Em todas as séries analisadas, os valores dos limites simulados apresentaram desviospadrão inferiores aos gastos totais, indicando que os valores simulados apresentam menor dispersão de dados, ao longo da sua distribuição.

As assimetrias, em módulo, foram inferiores a um e as curtoses foram positivas e inferiores a três. Tais constatações indicam que as séries possuem distribuição similares à distribuição normal, cuja confirmação decorre dos resultados do teste de detecção de normalidade das séries.

Os resultados do teste de Shapiro-Wilk, para detecção da normalidade, apresentaram probabilidades superiores a $22 \%$, ou seja, não houve rejeição da hipótese nula de que as séries possuem distribuição normal. Assim sendo, foi realizado o teste t de Student, para comparação entre os valores simulados e os realizados.

Na continuação, são apresentados os resultados do teste t de Student para a comparação entre os valores simulados e os gastos totais.

Tabela 2 - Resultados do teste $t$ de Student.

\begin{tabular}{cccccccc}
\hline $\begin{array}{c}\text { Despesas } \\
\text { Primárias }\end{array}$ & União & $\begin{array}{c}\text { Segurança } \\
\text { Pública }\end{array}$ & $\begin{array}{c}\text { Assistência } \\
\text { Social }\end{array}$ & $\begin{array}{c}\text { Previdência } \\
\text { Social }\end{array}$ & Saúde & Educação & Transporte \\
\hline Estatística $\mathrm{t}$ & 4,288 & 2,288 & 4,164 & 4,476 & 4,566 & 4,656 & 3,769 \\
Probabilidade & 0,003 & 0,051 & 0,003 & 0,002 & 0,002 & 0,002 & 0,006 \\
\hline
\end{tabular}

Fonte: Elaboração própria a partir das informações do Senado Federal (2017).

Os resultados dos testes t de Student confirmaram as percepções das análises gráficas, com exceção das séries relacionadas com a área de segurança pública. De acordo com os resultados, com a exceção da área supracitada, as probabilidades foram inferiores ao nível de significância de $5 \%$ e, portanto, houve rejeição da hipótese nula de igualdade entre os valores 
simulados e os gastos totais. Desse modo, além de diferenças nominais, estas são estatisticamente significantes.

A partir das evidências obtidas na análise gráfica e nos testes estatísticos, verifica-se que o teto dos gastos possui capacidade de garantir a criação de resultados primários positivos, desde que respeitados outros limites fiscais. Como o limite é individualizado por Poderes e entidades constitucionais e não por área de atuação governamental, não é possível quantificar o percentual no qual certas áreas serão afetadas.

Contudo, considerando os gastos totais, observou-se que a aplicação do limite impactaria uma parcela dos gastos obrigatórios. Conforme foi explicado anteriormente, a aplicação do teto de gastos é global e não por área de atuação governamental. Desse modo, caberá aos gestores federais definir quais as áreas e quais os cortes serão efetuados para que o limite seja cumprido.

As alterações de gastos obrigatórios não é tarefa simples, sendo necessária a alteração de dispositivos legais. Para alterar os gastos nas áreas de previdência social e da assistência social, por exemplo, o Poder Executivo enviou para a Câmara dos Deputados a PEC que altera dispositivos sobre a seguridade social (PEC n 287/2016) (CÂMARA DOS DEPUTADOS, 2016b). Nota-se que a adimplência do limite por parte do governo federal dependerá de reformas que tornem o crescimento de gastos obrigatórios compatíveis com a metodologia de atualização do limite da Emenda Constitucional n 95/2016, o NRF.

O NRF alterou os limites mínimos dos gastos com a educação e a saúde. Assim como ocorrerá em outras áreas de atuação governamental, até mesmo as sociais, os gastos obrigatórios das áreas da educação e da saúde podem sofrer cortes, respeitados os novos limites de aplicações mínimas, mas tal escolha dependerá do cenário de reformas de outras despesas obrigatórias.

Ainda em relação às áreas da saúde e da educação, observa-se que, considerando-se somente os novos limites para aplicações mínimas, não é possível determinar o nível de impacto que o NRF terá sobre tais áreas. Mesmo que a escolha dos gestores federais seja a de gastar somente os valores mínimos fixados, tais valores podem ser superiores aos antigos limites, caso o cenário seja de redução ou de crescimento abaixo do IPCA das receitas federais correspondentes. Somente no caso de crescimento das receitas acima do índice de correção dos limites e da aplicação apenas do limite mínimo é que as áreas da educação e da saúde seriam claramente prejudicadas em relação ao regime fiscal anterior. 


\section{Considerações finais}

Uma gestão fiscal responsável exige bastante controle das finanças públicas. Além de não poder gastar mais do que arrecada, o ente público precisa monitorar o comportamento das suas receitas e das suas despesas, adotando ajustes rápidos, assim que situações anormais sejam identificadas.

A LRF foi editada com o objetivo de aperfeiçoar as finanças públicas e permitir uma gestão fiscal austera e sustentável. Ao longo de pouco mais de quinze anos da edição da LRF, percebeu-se que algumas de suas premissas não estavam sendo observadas ou não eram suficientes para garantir uma boa gestão fiscal.

O NRF surge como uma tentativa de se recuperar as finanças públicas do governo federal, garantindo novos superávits primários, por meio do controle dos gastos federais. Dentre outras medidas, o NRF estabelece um teto de gastos, por intermédio de limites individualizados para os Poderes e entidades constitucionais, cujo crescimento estará limitado ao IPCA ou outro índice que vier a substituí-lo, por um período de vinte anos a partir de 2017.

Apesar de ser um avanço na busca de melhorar as condições financeiras do governo federal, a aplicação apenas do NRF não é condição suficiente e necessária para que ocorra tal melhoria.

De acordo com os resultados da simulação realizada, anteriormente apresentados, a aplicação de um teto de gastos nos moldes propostos pelo NRF implicará na redução de gastos obrigatórios da União. Estes gastos são aqueles nos quais os gestores não têm facilidades em alterar o seu montante. A redução ou a mudança no comportamento do crescimento de gastos obrigatórios necessitam de alterações em dispositivos legais que os instituíram.

Desse modo, o desafio inicial da aplicação do NRF, para os gestores federais, será a realização de reformas capazes de modificar o atual comportamento dos gastos obrigatórios em áreas como a previdência social e a assistência social, por exemplo. Sem tais reformas, os gastos obrigatórios destas áreas afetarão os demais, inclusive os de outras áreas sociais de atuação governamental.

Como o respeito ao teto impactará os gastos obrigatórios, segundo a simulação realizada, há evidências de que as áreas sociais serão afetadas pela aplicação do NRF. Não foi possível identificar o impacto em termos percentuais, pois este decorrerá da escolha dos gestores na elaboração da proposta orçamentária e das condições impostas pela despesa obrigatória.

As áreas de saúde e da educação ganharam novos limites de aplicações mínimas, de acordo com o NRF. Do modo que os limites foram estruturados não há certeza se tais áreas 
terão maior ou menor impacto do que outras áreas de atuação governamental. Quando comparados os limites anteriores e os do NRF, as áreas da saúde e da educação serão beneficiadas, enquanto as respectivas receitas públicas continuarem a crescer abaixo do IPCA. Caso contrário e se a escolha dos gestores for a de aplicações mínimas legais é que estas áreas terão sido prejudicadas.

Todavia, não era possível para o governo federal manter o ritmo de crescimento de suas despesas, sem comprometer a se tornar inadimplente. Considerando o atual estado das finanças públicas da União, o NRF parece ser uma medida necessária para evitar que esta se torne inadimplente.

Nos próximos exercícios, caberá aos gestores federais promover mudanças nas despesas obrigatórias, de maneira a adequá-las ao teto de gastos. Além disso, a redução do endividamento ajudará a diminuir o risco de inadimplência e de suas graves consequências para as finanças públicas, para o crescimento econômico e para a população.

Os gestores públicos brasileiros terão que analisar os custos e os benefícios de reduzir os gastos públicos, sem prejudicar a retomada do crescimento econômico e afetar muito a oferta de bens e serviços à população brasileira. O fiel cumprimento do teto de gastos, a realização de reformas relacionadas com as despesas obrigatórias e o compromisso de redução do nível de endividamento público podem auxiliar na retomada do crescimento econômico, após alguns anos.

As evidências relatadas na presente pesquisa estão limitadas pelas condições préestabelecidas para a realização da simulação. Outra limitação da pesquisa foi o período escolhido para análise, de 2008 a 2016, em razão do cenário recessivo da economia brasileira e da instabilidade no ambiente político nacional.

\section{Referências}

ALESINA, A. F.; PEROTTI, R. Budget deficits and budget institutions. In: J. M. POTERBA; J. HAGEN (Eds.). Fiscal institutions and fiscal performance (p. 13-36). Chicago: University of Chicago Press, 1999.

BAĞDIGEN, M.; ÇETINTAŞ, H. Causality between public expenditure and economic growth: the Turkish case. Journal of Economic and Social Research, v. 6, n. 1, p. 53-72, 2004.

BRASIL. Constituição da República Federativa do Brasil de 1988. Brasília, 1988. Lei Complementar n 101, de 4 de maio de 2000. Brasília, 2000. 
Emenda Constitucional $n^{\circ}$ 95, de 15 de dezembro de 2016. Brasília, 2016.

BRESSER-PEREIRA, L. C. O novo desenvolvimentismo e a ortodoxia convencional. São Paulo em Perspectiva, v. 20, n. 3, p. 5-24, 2006.

BRITO, G. A.; PIMENTEL, R. C. Risco nas operações de renda fixa. In: I. S. LIMA; G. A. LIMA; R. C. PIMENTEL. Curso de mercado financeiro (p. 183-197.) (2a ed.). São Paulo: Atlas, 2012.

CÂMARA DOS DEPUTADOS. PEC 241/2016. Altera o Ato das Disposições Constitucionais Transitórias, para instituir o Novo Regime Fiscal. 2016a. Brasília, 2016a.

. PEC 287/2016. Altera os arts. 37, 40, 109, 149, 167, 195, 201 e 203 da Constituição, para dispor sobre a seguridade social, estabelece regras de transição e dá outras providências. Brasília, 2016b.

CNN MONEY. Greece defaults on \$ 1.7 billion IMF payment. 2015. Disponível em: $<$ http://money.cnn.com/2015/06/30/news/economy/greece-imf-default $>$. Acesso em: 20 dez. 2016.

DATZ, G. Sovereign debt default. In: R. S. DENEMARK. The International Studies Encyclopedia, Blackwell Publishing, Blackwell Reference Online, 2014

FOLHA DE SÃO PAULO. Moody's é terceira agência de risco a retirar selo de bom pagador do Brasil. Mercado - O impeachment. 2016. Disponível em:

$<$ http://www1.folha.uol.com. br/mercado/2016/02/1742694-agencia-de-risco-moodys-tiraselo-de-bom-pagador-do-brasil.shtml.>. Acesso em: 07 nov. 2016.

GARCIA, G. Entenda a crise econômica. EBC - Agência Brasil. 2016. Disponível em: $<$ http:// agenciabrasil.ebc.com.br/economia/noticia/2016-05/entenda-crise-economica.>. Acesso em: 07 nov. 2016.

GROSSMAN, H. I.; HUYCK, J. B. Sovereign Debt as a Contingent Claim: Excusable Default, Repudiation, and Reputation. The American Economic Review, v. 78, n. 5, p. 10881097, 1988.

HILSCHER, J.; NOSBUSCH, Y. Determinants of Sovereign Risk: Macroeconomic Fundamentals and the Pricing of Sovereign Debt. Review of Finance, v. 14, n. 2, p. 235-262, 2010.

KEYNES, J. M. The general theory of employment, interest and money. 1936. Disponível em: $<$ http://etext.library.adelaide.edu.au/k/k44g/k44g.html.>. Acesso em: 25 fev. 2009.

NEW YORK TIMES. Explaining Greece’s debt crisis. 2016. Disponível em: $<$ http://www.nytimes.com/interactive/2016/business/international/greece-debt-crisis-euro .html? r=0.>. Acesso em: 22 nov. 2016.

REINHART, C. M.; ROGOFF, K. S. This time is different: eight centuries of financial folly. Princeton: Princeton University Press, 2009. 
; $ـ$ Growth in a time of debt. American Economic Review: Paper e Proceedings 2010, v. 100, n. 2, p. 1-9, 2010.

ROSE, A. K. One reason countries pay their debts: renegotiation and international trade. Journal of Development Economics, v. 77, n. 1, p. 189-206, 2005.

ROSE, A. K.; SPIEGEL, M. M. Cross-country causes and consequences of the 2008 crisis: international linkages and American exposure. Pacific Economic Review, v. 15, n. 3, p. 340$363,2010$.

SAMUELSON, P. A. The pure theory of public expenditure. The Review of Economics and Statistics, v. 36, n. 4, p. 387-389, 1954.

SECRETARIA DE ORÇAMENTO FEDERAL. Glossário. Brasília, 2016.

SECRETARIA DO TESOURO NACIONAL. Resultado primário e resultado nominal. Brasília, 2012.

Relatório mensal - Dívida Pública Federal - Novembro de 2016. Brasília, 2016.

SENADO FEDERAL. Orçamento da União - Siga Brasil. Brasília, 2017.

SUZART, J. A. A hipótese do grau de endividamento e o setor público: uma análise do nível de endividamento dos governos estaduais. Revista Contabilidade Vista e Revista, v. 23, n. 4, p. 73-101, 2012.

As informações contábeis governamentais e as agências de classificação de risco de crédito. Revista de Contabilidade e Controladoria, v. 6, n. 3, p. 108-126, 2014.

WALRAS, L. Compêndio dos elementos de economia política pura. São Paulo, Abril Cultural, 1983.

WORLD BANK. World DataBank - World development indicators. 2016. Disponível em: $<$ http://databank.worldbank.org/data/reports.aspx?source=2\&series=GC.DOD.TOTL.GD .ZS\&country=>. Acesso em: $20 \mathrm{dez} .2016$. 